\title{
Coastal vulnerability assessment based on video wave run-up observations at a mesotidal, steep-sloped beach
}

\author{
Michalis Ioannis Vousdoukas • Dagmara Wziatek • \\ Luis Pedro Almeida
}

Received: 27 March 2011 / Accepted: 21 July 2011 /Published online: 17 August 2011

(C) Springer-Verlag 2011

\begin{abstract}
Coastal imagery obtained from a coastal video monitoring station installed at Faro Beach, S. Portugal, was combined with topographic data from 40 surveys to generate a total of 456 timestack images. The timestack images were processed in an open-access, freely available graphical user interface (GUI) software, developed to extract and process time series of the cross-shore position of the swash extrema. The generated dataset of $2 \%$ wave run-up exceedence values $R_{2}$ was used to form empirical formulas, using as input typical hydrodynamic and coastal morphological parameters, generating a best-fit case RMS error of $0.39 \mathrm{~m}$. The $R_{2}$ prediction capacity was improved when the shore-normal wind speed component and/or the tidal elevation $\eta_{\text {tide }}$ were included in the parameterizations, further reducing the RMS errors to $0.364 \mathrm{~m}$. Introducing the tidal level appeared to allow a more accurate representation of the increased wave energy dissipation during low tides, while the negative trend between $R_{2}$ and the shore-
\end{abstract}

Responsible Editor: Michel Rixen

This article is part of the Topical Collection on Maritime Rapid Environmental Assessment

M. I. Vousdoukas $(\square)$

Forschungszentrum Küste,

Merkurstraße, 11,

30419 Hannover, Germany

e-mail:vousdoukas@fzk.uni-hannover.de

M. I. Vousdoukas $\cdot$ L. P. Almeida

CIMA, University of Algarve,

Campus de Gambelas,

8005 Faro, Portugal

D. Wziatek

Leibniz University Hannover,

Welfengarten $1 \mathrm{~A}$,

30167 Hannover, Germany normal wind speed component is probably related to the wind effect on wave breaking. The ratio of the infragravityto-incident frequency energy contributions to the total swash spectra was in general lower than the ones reported in the literature $E_{\text {infra }} / E_{\text {inci }}>0.8$, since low-frequency contributions at the steep, reflective Faro Beach become more significant mainly during storm conditions. An additional parameterization for the total run-up elevation was derived considering only 222 measurements for which $\eta_{\text {total }, 2}$ exceeded $2 \mathrm{~m}$ above MSL and the best-fit case resulted in RMS error of $0.41 \mathrm{~m}$. The equation was applied to predict overwash along Faro Beach for four extreme storm scenarios and the predicted overwash beach sections, corresponded to a percentage of the total length ranging from $36 \%$ to $75 \%$.

Keywords Wave run-up · Beach dynamics - Swash zone . Nearshore waves · Video imaging of waves · Image processing

\section{Introduction}

The accurate prediction of the wave run-up height $R$ is vital for the effective design of coastal protection works (e.g., Briganti et al. 2005) and beach nourishment projects (e.g., Dean 2001), as well as for the prediction of storm wave, surge, and tsunami effects (e.g., Korycansky and Lynett 2007) and the planning of efficient coastal management schemes (e.g., Kroon et al. 2007; Munoz-Perez et al. 2001; Xue 2001). Typically, coastal engineers and marine geologists estimate $R$ with the help of empirical formulations, using as input parameters the offshore wave height, period, and wave length, along with the beach slope. One of the earliest efforts to parameterize wave run up was the one of 
Hunt (1959), who, after considering measurements on wave tank tests for an extensive set of wave conditions, suggested the following relationship:

$R=H_{o} \xi$

where $H_{o}$ is the deep water significant wave height and $\xi$ the Iribarren number (Battjes 1974; Iribarren and Nogales 1949), given by:

$\xi=\frac{\beta}{\left(H_{o} / L_{o}\right)^{1 / 2}}$

where $\beta$ is the beach slope and $L_{\mathrm{o}}$ is the deep water wavelength.

Several other formulations have been proposed in the literature, expressing $R$ as a function of parameters like $H_{\mathrm{o}}$, $H_{\mathrm{o}}+H_{\mathrm{o}} \xi,\left(H_{\mathrm{o}} L_{\mathrm{o}}\right)^{1 / 2}, \beta\left(H_{\mathrm{o}} L_{\mathrm{o}}\right)^{1 / 2}$, and $\left(\beta H_{\mathrm{o}} L_{\mathrm{o}}\right)^{1 / 2}$ (e.g., Holman 1986; Douglass 1992; Synolakis 1987; Ruggiero et al. 2004), while the use of coastal video monitoring systems allowed the acquisition of wave run-up measurements for longer periods at various sites (Holman and Stanley 2007; Velegrakis et al. 2007; Vousdoukas et al. 2009a). Most of the above measurements are based on "timestack" images (e.g., Aagaard and Holm 1989; Holland and Holman 1993), which are representing the temporal pixel intensity variations ( $x$-axis) along a cross-shore transect of contiguous pixels that span the swash zone (y-axis). The correspondence between optical and in situ run-up has been well documented (Holland and Holman 1991; Holman and Guza 1984), and the approach is currently considered as "standard." Stockdon et al. (2006) combined information from ten different field sites and constitute the most extensive analysis of wave run-up upto-now, proposing the following relationship:

$R_{2}=1.1\left(0.35 \beta\left(H_{\mathrm{o}} L_{\mathrm{o}}\right)^{1 / 2}+\frac{\left[H_{\mathrm{o}} L_{\mathrm{o}}\left(0.563 \beta^{2}+0.004\right)\right]^{1 / 2}}{2}\right)$

Despite the fact that coastal video monitoring systems are operating at several sites worldwide, the number of studies based on wave run-up measurements is not proportional. Most of the existing ones are based on observations on US coasts (e.g., Ruggiero et al. 2001; Raubenheimer and Guza 1996), with the exception of some North Sea studies at Dutch and Danish sites (e.g., Aagaard and Holm 1989; Ruessink et al. 1998). According to our knowledge, recent efforts to test existing wave run-up parameterizations against extensive field data from the European Atlantic coast are few. On the other hand, the geological history, the tidal and climatic conditions, as well as the wave climate may vary significantly among continents and sites, demanding further investigation.

One of the limiting factors in generating wave run-up measurements from timestack images is the fact that automatic extraction is not always robust. As a result, manual supervision is required, implying increased processing times. Given the foregoing context, the objective of this contribution is to (a) present a semi-automatic procedure for the generation of wave run-up data from timestack images and apply it in imagery acquired from a reflective beach in the S Portuguese coast; (b) present/ discuss the dataset and compare against existing parameterizations, as well as new ones considering additional parameters like the tidal elevation and the wind speed; and (c) use the site-specific parameterization to assess the alongshore vulnerability to overwash events, using an approach with general applicability.

\section{Study area}

Faro Beach is located in the mesotidal, NW-SE oriented sandy Ancão Peninsula (S Portugal, Fig. 1). Tides in the area are semi-diurnal, with average ranges of $2.8 \mathrm{~m}$ for spring tides and $1.3 \mathrm{~m}$ during neap tides, although a maximum range of $3.5 \mathrm{~m}$ can be reached. The offshore wave climate is moderate to high, with an average annual significant offshore wave height $H_{\mathrm{s}}=0.92 \mathrm{~m}$ and average peak wave period $T_{\mathrm{p}}=$ $8.2 \mathrm{~s}$ (Almeida et al. 2011a, b; Ferreira et al. 2009). Waves are mostly west-southwest (occurrence $\sim 71 \%$ ), while shorter period SE waves by regional winds are also frequent $(23 \%)$. Storm events in the region are considered when the significant offshore wave height exceeds $3 \mathrm{~m}$ and typically correspond to less than $1 \%$ of the offshore wave climate.

Faro Beach is essentially a reflective beach (see classification of Wright and Short 1984) with beach-face slopes typically above $10 \%$ and varying from $6 \%$ to $15 \%$, with a tendency to decrease eastward along the beach where a "low tide terrace" beach state is reached (Almeida et al. 2010). Sediments are medium to very coarse, moderately well-sorted sands (see classification of Folk 1980) with $d_{50} \sim 0.5 \mathrm{~mm}$ and $d_{90} \sim 2 \mathrm{~mm}$. While the eastern sector of Faro Beach is accreting and vegetated foredune development is evident, the central and western parts tend toward erosion, with much of their natural dune ridge having been overtaken by urban development. As a result, a large part of the ocean front has been artificially stabilized with sea walls, which are often overwashed during spring tides or under storm conditions (Almeida et al. 2011b).

\section{Methods}

3.1 Wave, tidal, wind, and topographic data

Offshore wave data were provided by a wave buoy, deployed offshore Faro Beach at $93 \mathrm{~m}$ depth (Fig. 1a) by 

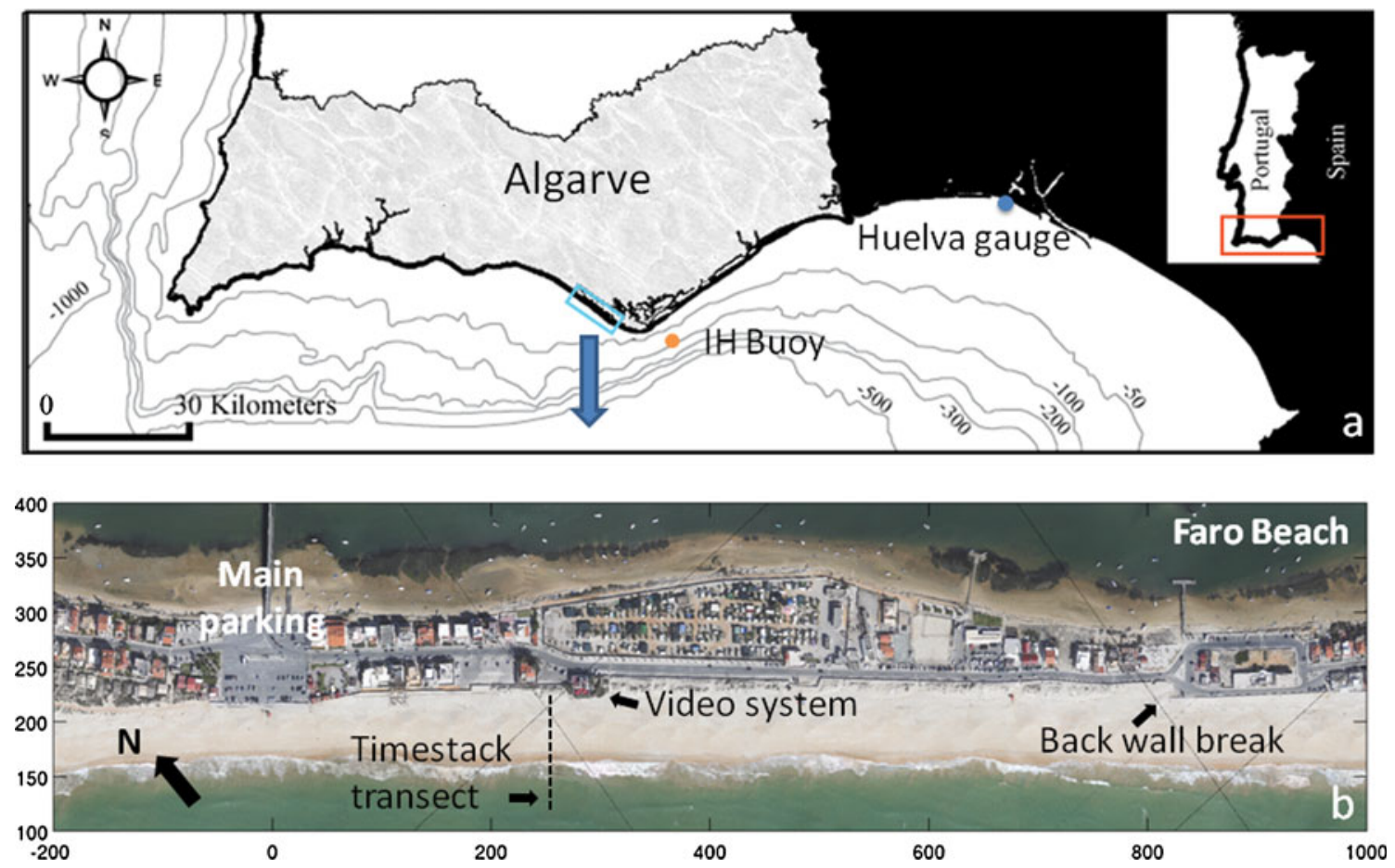

Fig. 1 a Map of the Algarve region (S Portugal) showing the locations of the study area (rectangle), the IH wave buoy, and the Huelva tidal gauge. b Mosaic of aerial photographs of the study area, rotated by $39^{\circ}$ counterclockwise. The location of the video station and the cross-shore transect considered for swash motion monitoring are shown, along with the main parking area and another section where the wall is discontinuous and overwash events are frequent

which took place in November 2009, while topographic data were collected using an RTK DGPS. Forty topographic surveys took place during the period from September 2009 to April 2010, mainly during spring tides and cover a wide range of wave conditions. All topographic data were initially acquired in the Datum 73 (EPSG:27493) coordinate system and were subsequently rotated so that the $x$ - and $y$-axes corresponded to cross-shore and alongshore dimensions, respectively. The rotation angle was $39^{\circ}$ anti-clockwise around the origin of the new coordinate system: $[x, y]=[12,255,-295,575]$ in Datum 73 . Grids were generated from each topographic survey with a resolution of $0.2 \mathrm{~m}$. The measuring errors have been estimated (a) using either fixed points of known coordinates and (b) measuring repeatedly the same beach transect. The accuracy was estimated to be in the range of $5 \mathrm{~cm}$ for both vertical and horizontal dimensions.

\subsection{Coastal video imagery}

A video monitoring station installed on the roof of a building facing Faro Beach was acquiring coastal zone imagery from 1 February 2009 to 30 May 2010, for 10 min every hour during daylight, with an acquisition frequency of $1 \mathrm{~Hz}$. Imagery from the summer period (14 June 2009-1 September 2009) was not considered 
due to intense summer occupation of the beach. The system consists of two Mobotix M22, 3.1 megapixel $(2,048 \times 1,536$ pixel resolution), Internet Protocol cameras, connected to a PC with permanent internet access. The elevation of the center of view is around $20 \mathrm{~m}$ above MSL. The two cameras provide a $\sim 90^{\circ}$ view of the coast westward of the cameras, covering an alongshore length of $500 \mathrm{~m}$, including the area selected for topographic monitoring (Vousdoukas et al. 2011b).

For this study, timestack images for wave run-up measurements were generated on an hourly basis. Standard transformation from image to world coordinates (image geo-rectification) took place after applying a lens distortion correction (Bouguet 2007) and considering the $3 \times 4$ perspective transformation matrix $P$, using homogeneous coordinates (Hartley and Zisserman 2006). The procedure followed is described in detail in Vousdoukas et al. (2011) and in the extensive literature on coastal video monitoring (e.g., Holman and Stanley 2007; Smith and Bryan 2007; Pearre and Puleo 2009 and references therein). Geo-rectification errors due to camera movement have been corrected following an automatic procedure based on feature matching (Vousdoukas et al. 2011b).
The $x, y$, and $z$ coordinates of the desired beach transect obtained from the topographic data were transformed into image dimensions to define a line along the original images. Pixel intensities were sampled along this line during image progressions of $10 \mathrm{~min}$ to produce the final timestack images (Fig. 2), with $x$ - and $y$-axes indicating time and cross-shore distance, respectively. The cross-shore resolution of the timestack images was $0.2 \mathrm{~m}$, equal to the minimum pixel footprint along the monitored transect, and images were generated each hour on days when topographic surveys took place. On occasions when no major morphological changes were detected between days, image data from the day following a topographic survey were also used. Therefore, although run-up was not measured every day, the approach used served to diminish geolocational artifacts in the obtained wave run-up measurements.

\subsection{Timestack processing}

All timestack images were processed in an open-access GUI software (https://sourceforge.net/projects/guitimestack; see "Appendix" and Fig. 2), specially developed in MATLAB to extract and process time series of the cross-

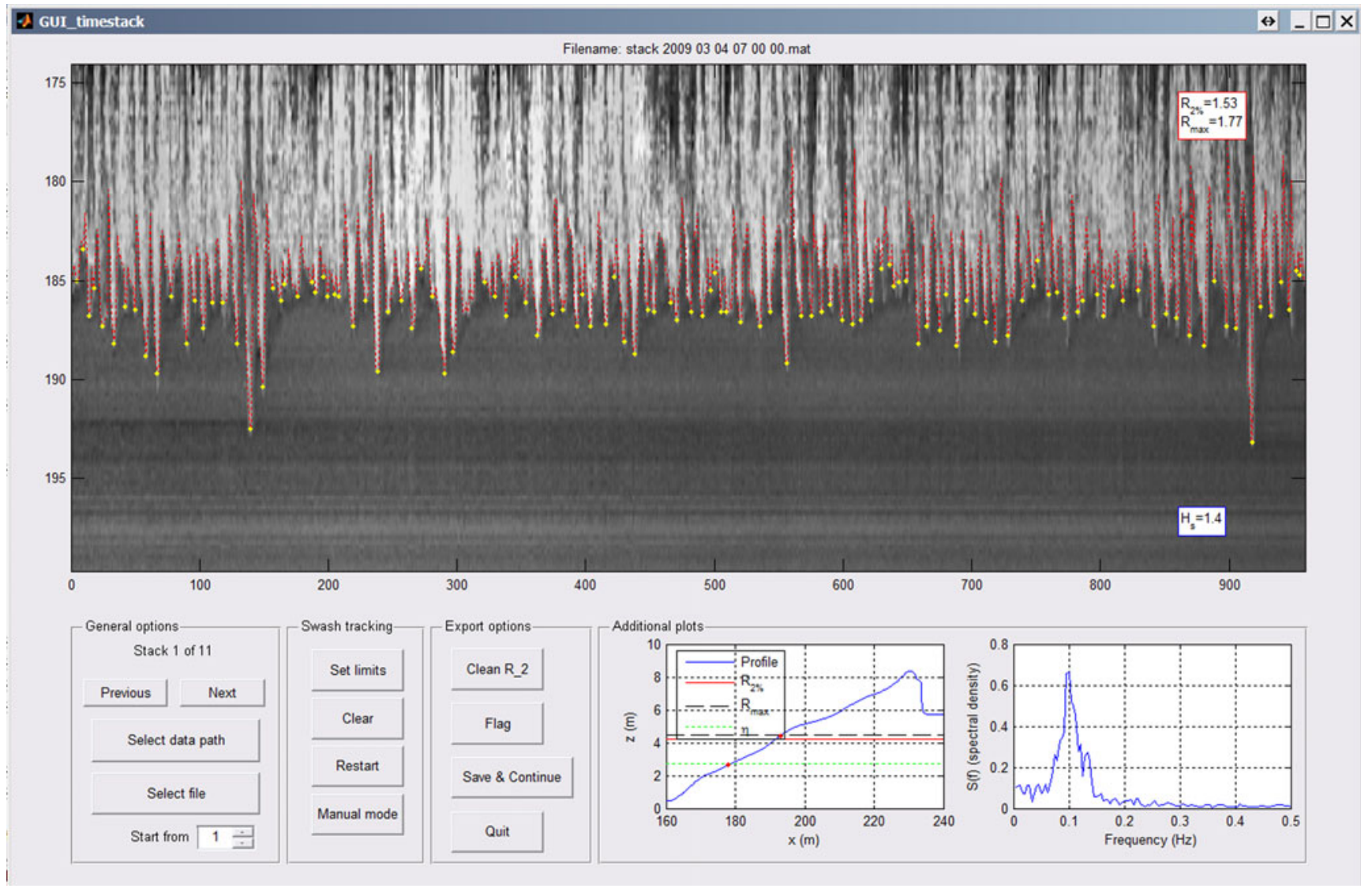

Fig. 2 Snapshot of the GUI timestack processing software used. Red lines indicate the swash front motions, and yellow dots the discrete maxima considered for the estimation of $2 \%$ exceedence values 
shore position of the swash extrema (Fig. 2). The extraction of the swash time series is based on a modified Otsu's thresholding method (Otsu 1979), while the GUI environment allows rigorous manual quality control and corrections when necessary. The obtained values, expressing cross-shore coordinates, were transformed into elevations using the topographic information from the daily field surveys, assuming that there was little morphological change during tidal cycles. The estimated elevations express the total wave run-up level $\eta_{\text {total }}(t)$, which can be defined as:

$\eta_{\text {total }}(t)=\eta_{\text {tide }}+\eta_{\mathrm{su}}+\eta_{\mathrm{s}}+S_{\mathrm{sw}}(t)$

where $\eta_{\text {tide }}$ and $\eta_{\text {su }}$ are the tidal and surge heights, respectively; $\eta_{\mathrm{s}}$ is the maximum wave set-up height; and $S_{\mathrm{sw}}(t)$ is the swash-induced water-level fluctuation (Vousdoukas et al. 2009a, 2011a; Stockdon et al. 2006).

Wave run-up height $R$ is usually defined as a discrete-intime variable, containing the local maxima of the water-level fluctuation time series $\eta_{\mathrm{sw}}(t)$, with respect to still water level:

$\eta_{\mathrm{sw}}(t)=\eta_{\mathrm{s}}+S_{\mathrm{sw}}(t)$

Given the distance of the Huelva gauge from the study area, only the tidal variations were taken into consideration, implying that the surge and wave set-up heights $\eta_{\mathrm{su}}$ and $\eta_{\mathrm{s}}$ in Eq. 4, could not be directly measured, while $S_{\mathrm{sw}}(t)$ was available after de-trending $\eta_{\text {total }}(t)$. For the above reasons, $\eta_{\mathrm{sw}}(t)$ was obtained according to Eq. 5 using the fluctuating component $S_{\text {sw }}(\mathrm{t})$ and considering wave set-up values estimated from wave-propagation model simulations on a typical winter beach profile for the area and using instantaneous wave and tidal parameters as input. The model is solving high-order Boussinesq equations, based on the $x-z$ integrated momentum equations (Mei 1994; Veeramony and Svendsen 2000). The model is using the surface roller concept for wave energy dissipation with surface and thickness calculated according to Schaffer et al (1993) (for further details, see Vousdoukas et al. 2009b; Karambas and Koutitas 2002 and references therein).

\subsection{Post-processing}

Two percent exceedence $\left(R_{2}\right)$ values were estimated from the $\eta_{\mathrm{sw}}(t)$ series after extracting the local maxima, expressing the uppermost position of each swash event (swash excursion maxima). Similarly, all the total run-up elevation $\eta_{\text {total }}(t)$ values discussed below correspond to $2 \%$ exceedence values, $\eta_{\text {total,2}}$, unless otherwise indicated. The foreshore beach slope $\beta_{\mathrm{s}}$ was estimated by applying a linear regression fit on the profile section with elevations ranging between $z_{\beta}=\eta_{\text {tide }} \pm$ $2 \sigma\left(S_{\mathrm{sw}}(t)\right)$, where $\sigma$ expresses standard deviation.

The $R_{2}$ measurements were used to form empirical wave run-up parameterizations using as input previously proposed expressions (e.g., Holman 1986; Ruggiero et al. 2001; Hunt 1959; Stockdon et al. 2006; Synolakis 1987; e. g., Douglass 1992), through iterative fitting and using the RMS errors as an indication of the predictive skill of each parameterization. The statistical significance of the difference between the resulting expressions was assessed applying two-sample $t$ tests on pairs of the absolute prediction errors. The parameters tested were $H_{\mathrm{o}}, H_{\mathrm{o}} \xi, H_{\mathrm{o}}+$ $H_{\mathrm{o}} \xi,\left(H_{\mathrm{o}} L_{\mathrm{o}}\right)^{1 / 2}, \beta\left(H_{\mathrm{o}} L_{\mathrm{o}}\right)^{1 / 2}, \eta_{\text {tide }}, U_{w, x}, \Omega,\left(\beta H_{\mathrm{o}} L_{\mathrm{o}}\right)^{1 / 2}$, as well as the Stockdon et al. (2006) formula. The non-dimensional sediment fall velocity $\Omega$ was estimated according to the following equation:

$\Omega=\frac{H_{b}}{w_{s} T_{p}}$

where $w_{\mathrm{s}}$ and $T_{\mathrm{p}}$ are the sediment fall velocity tidal and peak wave period, respectively, and $H_{\mathrm{b}}$ the breaker height, estimated in the present case by the wave-propagation model. The sediment fall velocity was estimated according to Fredsoe and Deigaard (1992), considering mean grain size for the area $d_{50}=0.5 \mathrm{~mm}$. Spectral analysis was applied to the $S_{\mathrm{sw}}(t)$ time series, and infragravity and incident frequency band energy contributions were estimated by integrating the spectra energy densities considering a cutoff frequency of $0.05 \mathrm{~Hz}$

\section{Results}

\subsection{General}

All (456) timestack images were processed and the automatically extracted swash time series were manually corrected using the GUI interface, when necessary. The image-processing algorithm's performance occasionally produced rogue measurements when human activity or rain affected image quality. The generated dataset covered the year long range of beach states and wave forcing in the study area, excluding the summer season, during which beach occupation made image acquisition impossible. The significant wave height $H_{\mathrm{s}}$ values were varying between $0.17 \mathrm{~m}<H_{\mathrm{s}}<3.6 \mathrm{~m}$, around a mean of $1.4 \mathrm{~m}$ and mode of $0.4 \mathrm{~m}$ (Fig. 3a), while the peak wave period fluctuated from $T_{\mathrm{p}}=2.7 \mathrm{~s}$ to $T_{\mathrm{p}}=16.5 \mathrm{~s}$ with the average and the mode being equal to 9.5 and $4.2 \mathrm{~s}$, respectively (Fig. $3 \mathrm{~b}$ ). The beachface slope $\beta$ varied from $4 \%$ to $15 \%$, around a mean of $10.3 \%$ and a mode of $10 \%$ (Fig. 3c).

The Iribarren number varied from $\xi=0.3$ to $\xi=2.8779$ (Fig. 3d), and $81 \%$ of the measurements indicate the presence of "plunging breakers" $(0.5<\xi<3.3)$ and the remaining 19\% "spilling" ones (e.g., US Army Corps of Engineers 2002). The non-dimensional sediment fall velocity varied from $\Omega=0.71$ to $\Omega=6.54$ around a mean value of 3.15 (Fig. 3e), which implies that $87 \%$ of the measurements correspond to "intermediate" beach state $(1<\Omega<6), 12 \%$ to 

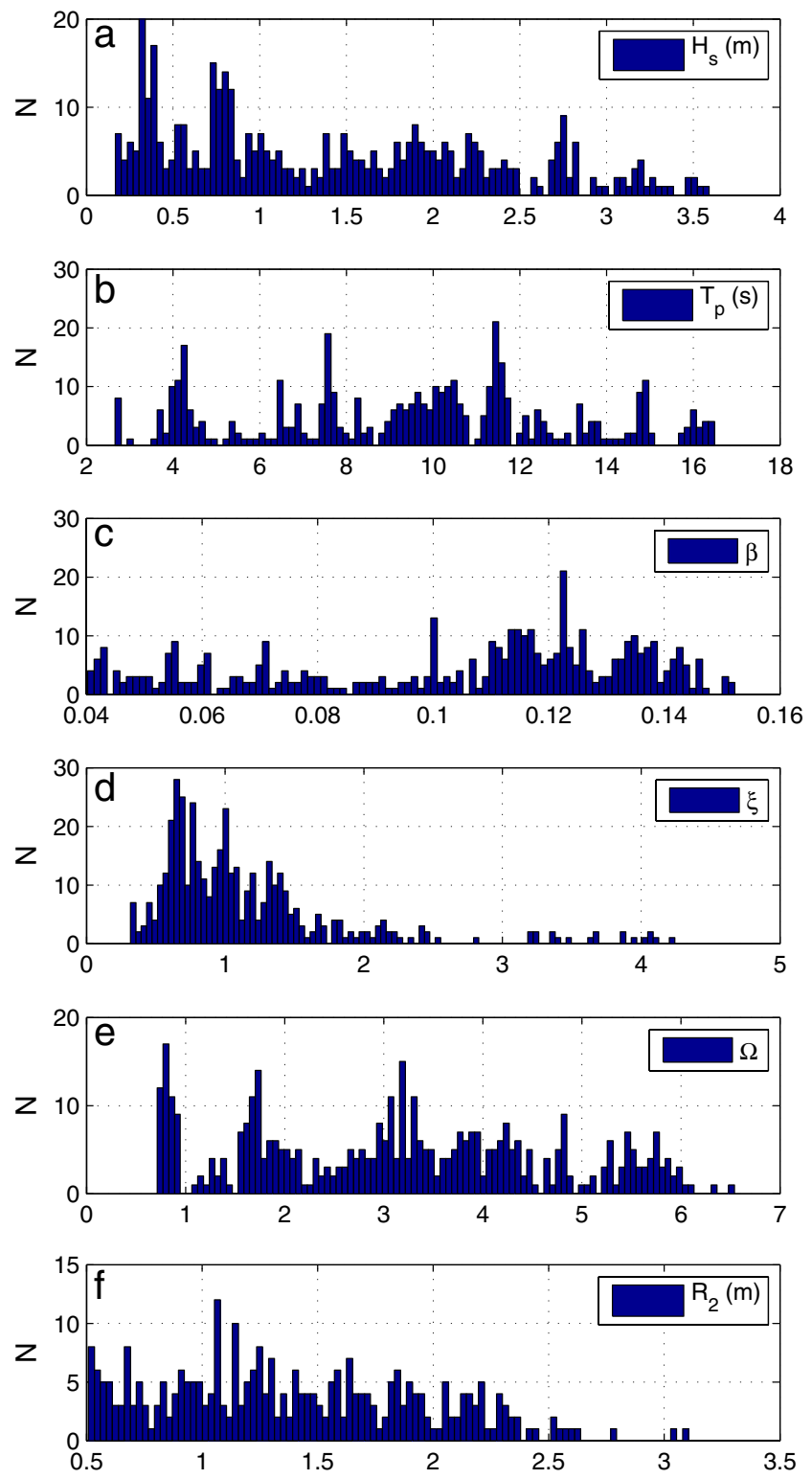

Fig. 3 Histograms of the significant wave height (a), peak wave period (b), beach-face slope (c), Iribarren number (d), non-dimensional sediment fall velocity (e), and $2 \%$ exceedence wave run-up height for the measurements considered. The number of bins considered is 100

"reflective" $(\Omega<1)$, and $1 \%$ to "dissipative" one (Wright and Short 1984).

Considering the shore-normal wind component the highest wind speed to and from the shore was $U_{w, x}=21 \mathrm{~m} / \mathrm{s}$ and $U_{w x}=-8.6 \mathrm{~m} / \mathrm{s}$, respectively, while for $60 \%$ of the cases $U_{w, x}$ was positive (toward the shore). The minimum $2 \%$ wave run-up exceedence value measured was $R_{2}=0.51 \mathrm{~m}$ and the maximum $R_{2}=3.11 \mathrm{~m}$, with a mean of $R_{2}=1.39 \mathrm{~m}$ (Fig. 3f). The range of the total run-up elevation $2 \%$ exceedence values was $2.3 \mathrm{~m}<\eta_{\text {total }, 2}<7.33 \mathrm{~m}$ around a mean of 4.52 with the maximum value implying overwash along some sections of Faro Beach.

\subsection{Wave run-up parameterization}

Several parameters were tested to provide an optimal fit to the measurements; an overview is given in Table 2. The best performance was obtained by the following formula with RMS error equal to $0.39 \mathrm{~m}$ (Table 2; Fig. 4a):

$R_{2}=0.53 \beta\left(H_{o} L_{o}\right)^{1 / 2}+0.58 \xi \sqrt{\frac{H_{o}^{3}}{L_{o}}}+0.45$

However, the following two formulas resulted in similar RMS errors RMSE $=0.4 \mathrm{~m}$ (Table 2 and Fig. $4 \mathrm{~b}, \mathrm{c}$ ), and the differences were not statistically significant (paired samples $t$ test, 5\% significance level):

$R_{2}=0.57 H_{o} \xi+0.02 H_{o}+0.45$

$R_{2}=0.58 H_{o} \xi+0.46$

The Stockdon06 formula resulted in slightly higher RMS errors as it showed a tendency to underestimate $R_{2}$, and even though the differences were statistically significant (paired samples $t$ test, 5\% significance level), they did not exceed $6 \mathrm{~cm}$ (Fig. 4d).

The $R_{2}$ prediction capacity improved when the shorenormal wind speed component $U_{w, x}$ and/or the tidal elevation $\eta_{\text {tide }}$ were included in the parameterizations. It is interesting that the linear regression fit using only the $U_{w, x}$ as independent variable resulted in RMS around $0.55 \mathrm{~m}$, which when was reduced to $0.51 \mathrm{~m}$ when combined with $\eta_{\text {tide }}$ (Table 2). As a result, the RMS error for the best-fit case was reduced by $1.1 \%$ when $U_{w, x}$ was included in the parameterizations $\left(\mathrm{RMSE}_{\text {best }}=0.391 \mathrm{~m}\right.$; see also Table 2) and by $8.1 \%$ when $\eta_{\text {tide }}$ was considered $\left(\mathrm{RMSE}_{\text {best }}=\right.$ $0.366 \mathrm{~m}$ ). The latter case was found to result in statistically significant predictive capacity (paired sample $t$ test, $5 \%$ significance level), as was also the case for the overall bestfit case, occurring when both factors were included according to the following equation $\left(\mathrm{RMSE}_{\text {best }}=0.364 \mathrm{~m}\right.$, $8.4 \%$ reduction; see also Table 2 ):

$$
\begin{aligned}
R_{2} & =0.503 \beta\left(H_{o} L_{o}\right)^{1 / 2}+0.878 \xi \sqrt{\frac{H_{o}^{3}}{L_{o}}}-0.016 U_{w, x} \\
& +0.188 \eta_{\text {tide }}+0.457
\end{aligned}
$$

where $\eta_{\text {tide }}$ expresses the tidal water-level variations relatively to the MSL.

\subsection{Effect of the tidal variations}

All wave run-up height measurements were separated according to the $\eta_{\text {tide }}$ (positive-negative) and additional iterative fitting efforts took place resulting in further reduction of the RMS errors. The best case for high tide $\left(\eta_{\text {tide }}>0\right)$ resulted in 
Table 2 Summary of efforts to parameterize the $2 \%$ exceedence for the run-up height $R_{2}$ on the grounds of the deep water significant wave height $H_{\mathrm{o}}$, offshore wavelength $L_{\mathrm{o}}$, the Iribarren number $\xi$, the beach slope $\beta$, the tidal elevation $\eta_{\text {tide, }}$ and the cross-shore wind speed component $U_{w, x}$

\begin{tabular}{|c|c|c|c|c|}
\hline & - & $U_{w, x}$ & $\eta_{\text {tide }}$ & $U_{w, x}, \eta_{\text {tide }}$ \\
\hline$H_{0}$ & 0.50 & 0.50 & 0.45 & 0.57 \\
\hline$H_{0} \xi$ & 0.40 & 0.39 & 0.37 & 0.41 \\
\hline$\beta \sqrt{H_{o} L_{o}}$ & 0.41 & 0.44 & 0.38 & 0.37 \\
\hline$\sqrt{H_{o} L_{o}}$ & 0.53 & 0.47 & 0.49 & 0.41 \\
\hline$\eta_{\text {tide }}$ & 1.42 & 0.51 & - & - \\
\hline$U_{w, x}$ & 0.55 & - & 0.51 & - \\
\hline $1.1\left(0.35 \beta\left(H_{o} L_{o}\right)^{1 / 2}+\frac{\left[H_{o} L_{o}\left(0.563 \beta^{2}+0.004\right)\right]^{1 / 2}}{2}\right)$ & 0.46 & 0.40 & 0.37 & 0.37 \\
\hline$\Omega$ & 0.54 & 0.54 & 0.49 & 0.49 \\
\hline$p_{1} H_{o} \xi+p_{2} H_{o}$ & 0.40 & 0.39 & 0.37 & 0.39 \\
\hline$p_{1} H_{o}+p_{2} H_{o} \xi+p_{3} \sqrt{\beta H_{o} L_{o}}+p_{4} \sqrt{H_{o} L_{o}}$ & 0.43 & 0.40 & 0.37 & 0.38 \\
\hline$p_{1} \beta\left(H_{o} L_{o}\right)^{1 / 2}+p_{2} \xi \sqrt{\frac{H_{o}^{3}}{L_{o}}}$ & 0.40 & 0.39 & 0.37 & 0.36 \\
\hline
\end{tabular}

The values express RMS errors (meters) after iterative fitting and $p_{\mathrm{n}}$ express fitting coefficients. Iterative fitting was applied to all parameters apart from the Stockdon06 formula

RMSE $\sim 0.39 \mathrm{~m}$ which was further decreased to $0.33 \mathrm{~m}$ when $U_{w, x}$ was also considered (see also Fig. 5a):

$R_{2, H T}=0.67 \beta\left(H_{o} L_{o}\right)^{1 / 2}-0.31 \xi \sqrt{\frac{H_{o}^{3}}{L_{o}}}-0.01 U_{w, x}+0.58$

Similarly for the wave run-up height measurements corresponding to "low tide" $\left(\eta_{\text {tide }}<0\right)$, the following parameterization resulted in RMSE $\sim 0.37 \mathrm{~m}$ (see also Fig. 5 b):

$R_{2, L T}=0.29 \beta\left(H_{o} L_{o}\right)^{1 / 2}+3.14 \xi \sqrt{\frac{H_{o}^{3}}{L_{o}}}-0.001 U_{w, x}+0.24$

\subsection{Wave run-up spectra}

The $E_{\text {infra }} / E_{\text {inci }}$ ratio of the infragravity-incident wave run-up energy contributions varied around a mean value of $E_{\text {infra }} / E_{\text {inci }}=$ 0.55 (Fig. 6a), while the average peak run-up frequency for all the swash time series was $f_{\mathrm{p}, \mathrm{sw}}=0.057 \mathrm{~s}^{-1}$ (Fig. 6b). The infragravity and incident band contributions to the total wave run-up energy seemed to be similar, with the exception of some cases, which were related mostly to high tide conditions, for which $E_{\text {inci }}$ was dominating the swash spectra (Fig. 7). Most of the cases for which the peak run-up frequency was at the infragravity band $\left(f_{\mathrm{p}, \mathrm{sw}}<0.05 \mathrm{~s}^{-1}\right)$, the Iribarren number was $\xi<1$ and higher Iribarren number values were frequently related to $f_{\mathrm{p}, \mathrm{sw}}$ around $0.06 \mathrm{~s}^{-1}$. The ratios of the peak run-up to peak offshore wave period indicated that major wave run-up peak period down-shifting occurred for $\xi<1.5$ (Fig. 8). No dependency of the peak run-up frequency to the nondimensional sediment fall velocity was discerned; however, most values $f_{\mathrm{p}, \mathrm{sw}}$ higher than $0.005 \mathrm{~s}^{-1}$ were found to be related to water levels about MSL (Fig. 9).

\subsection{Dune overwash predictions}

Following, $222 \eta_{\text {total,2 }}$ measurements which exceeded $\eta_{\text {total, } 2}>2 \mathrm{~m}$ above MSL were processed in an effort to improve the predicting capacity of dune overwash events. The best-fit case, expressed by the following equation, resulted in RMS error around $0.41 \mathrm{~m}$ :

$$
\begin{aligned}
\eta_{\text {total }, 2} & =0.681 \beta\left(H_{o} L_{o}\right)^{1 / 2}-0.235 \xi \sqrt{\frac{H_{o}^{3}}{L_{o}}} \\
& +0.782 \eta_{\text {tide }}+0.497
\end{aligned}
$$

The equation was applied to predict overwash along Faro Beach for four extreme storm scenarios. Apart from the wave and water-level parameters given in Table 1 , the average beach-face slope $\beta=0.1$ was considered to complete the necessary input parameters. Comparison of the predicted $\eta_{\text {total,2 }}$ values with the LIDAR DEM, for a 5-year return period storm, resulted in predicted overwash along $37 \%$ of the study area (Fig. 11a). The maximum excess runup elevation $\eta_{\text {total,2 }}-z_{\text {dune }}$ crest was $0.75 \mathrm{~m}$, while the average was $0.17 \mathrm{~m} ; z_{\text {dune crest }}$ expresses the alongshore variations of the dune crest elevation. The results highlight the parking area (indicated by black line, $y \sim 0$, Fig. 11a) and another section where the wall backing the beach is interrupted (indicated by black line, $y \sim 850$ ), as the beach sections with the highest possibility for overwash occurrence and as additional vulnerable points were identified the locations where the dunes are interrupted to allow access to the beach though stairs on the wall backing the beach (indicated by arrows, Fig. 11a). 

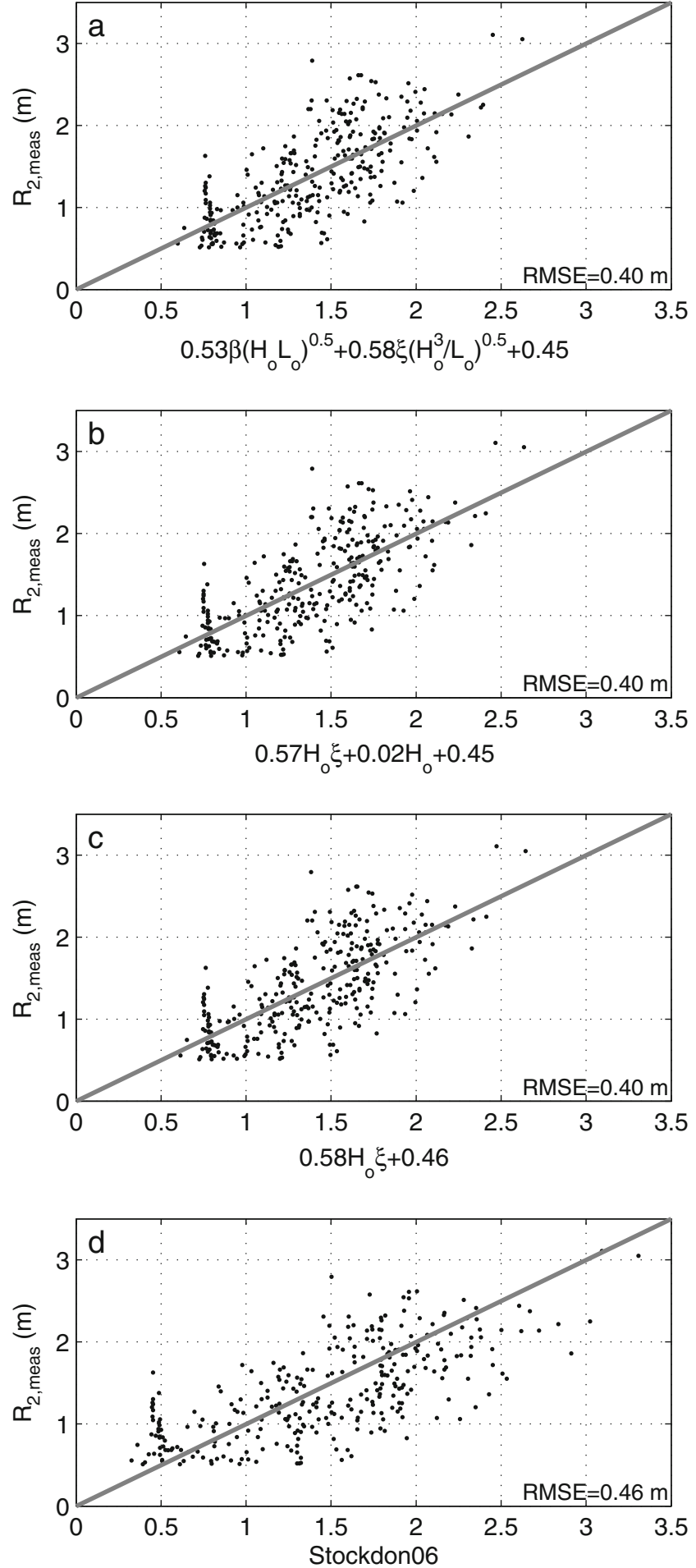

Fig. 4 Scatter plots showing the three more accurate $R_{2}$ wave run-up parameterizations (a-c; $x$-axis; see label for equation), as well as the values estimated with the Stockdon06 formula (d), versus the measurements ( $y$-axis)

Considering a 10 -year return period storm, the percentage of predicted overwashed beach increased to $49 \%$, with maximum and average excess run-up elevation equal to 1 and $0.35 \mathrm{~m}$, respectively. The predictions also indicated that
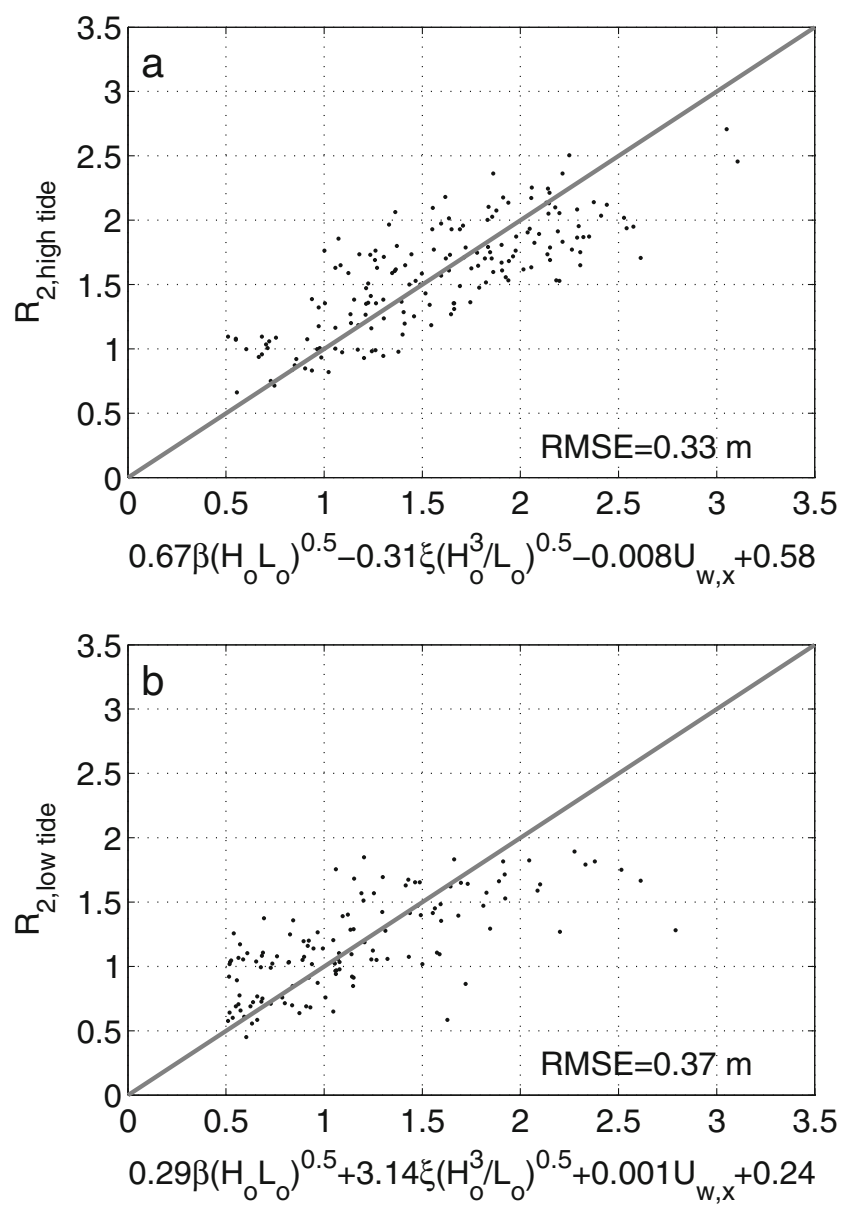

Fig. 5 Scatter plots showing the best-fit $R_{2}$ wave run-up parameterizations ( $x$-axis; see label for equation) vs the measurements ( $y$-axis), corresponding to water levels above (a) and below MSL (b)

overwash of the dunes found west of the parking area, while significant overwash was predicted along the area with $790 \mathrm{~m}<y<1,000 \mathrm{~m}$ where the dune has been overtaken by house construction and the elevation of the back-wall is low (Fig. 11b).

The percentage of predicted overwashed beach for a 25 year return period storm was $54 \%$, and the maximum and mean excess run-up elevation reached 1.34 and $0.65 \mathrm{~m}$, respectively. The predicted "weak spots" were similar but appeared to be broader (Fig. 11c). For a one-in-50-year storm event, the overwashed beach length is predicted to cover $75 \%$ of the total, with maximum and mean excess run-up elevation reaching 1.78 and $0.84 \mathrm{~m}$, respectively (Fig. 11d).

\section{Discussion}

\subsection{Wave run-up parameterization}

Estimating the wave run-up height from empirical parameterizations is a standard approach for coastal engineers and 

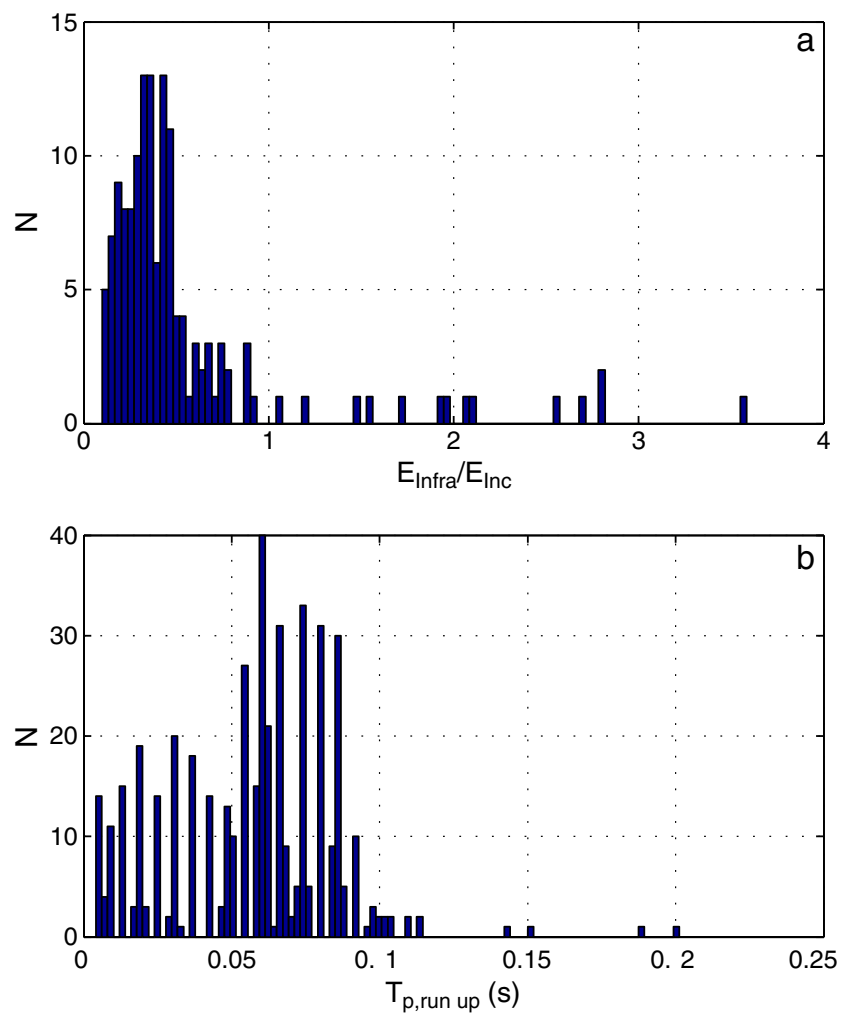

Fig. 6 Histograms (number of bins=100) of the infragravity-toincident band wave run-up energy contributions ratio $E_{\text {infra }} / E_{\text {inci }}(\mathbf{a})$ and the peak run-up frequency (b) for all the studied time series

researchers, which, however, has several limitations and may involve inaccuracies. The above is also shown by the scatter of the values when compared to the ones estimated from formulations (Figs. 4 and 5), as well as from the fact that maximum absolute errors often reached $1 \mathrm{~m}$. Waves interact

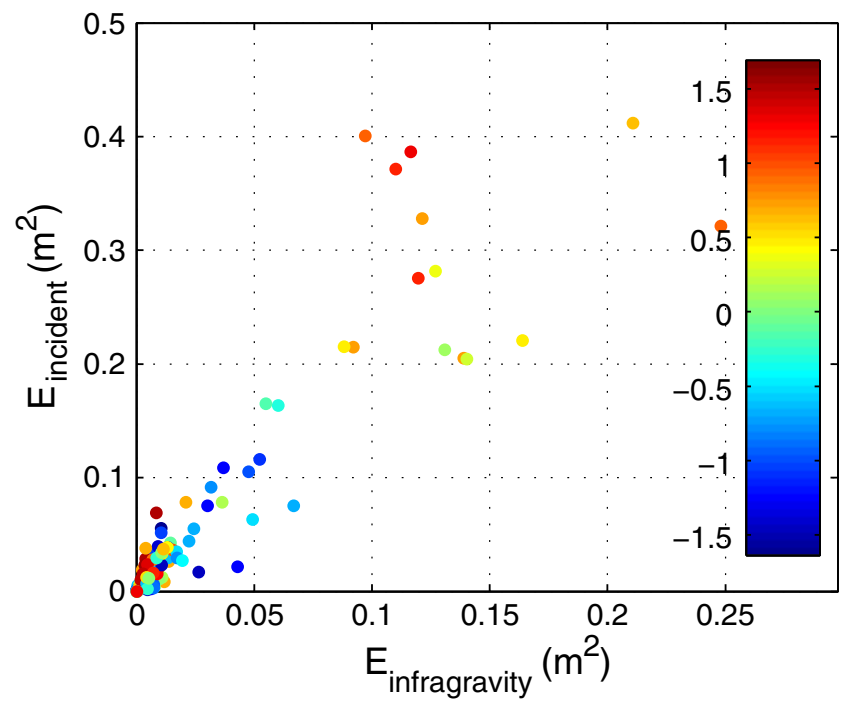

Fig. 7 Scatter plot of infragravity $\left(E_{\text {infra }}\right)$ vs incident band $\left(E_{\text {inci }}\right)$ wave run-up energy contributions. Color scale expresses the tidal level

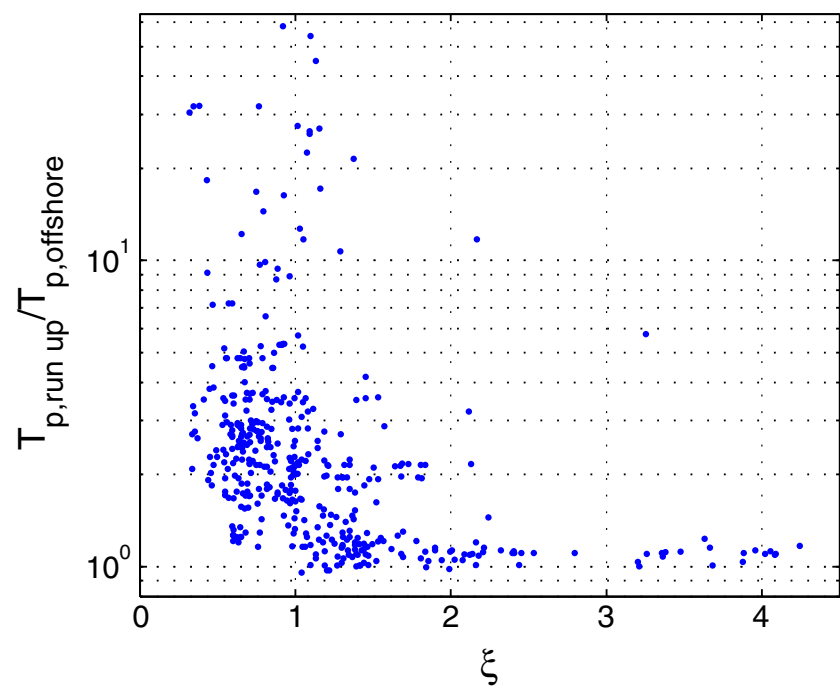

Fig. 8 Scatter plot of the ratio of the peak run-up period to peak offshore wave period vs the Iribarren number $\xi$

with the bathymetry as they propagate to the coast and are gradually transformed to skewed and following, asymmetric breaking waves, before they eventually trigger wave run up.

Predicting swash motions when the wave characteristics at the shoreline are known is relatively straightforward, and swash excursions have been well described by ballistic models. The above approach is based on translating swash energy/momentum into wave run-up height, considering the beach-face friction and slope (e.g., Hunt 1959) and has been proved to be accurate, despite uncertainties, i.e. the ones related to the interaction of individual waves (e.g., Larson et al. 2004). On the other hand, wave energy dissipation due to shoaling/breaking is more difficult to quantify, especially since the surf zone is often a denied environment for field measurements.

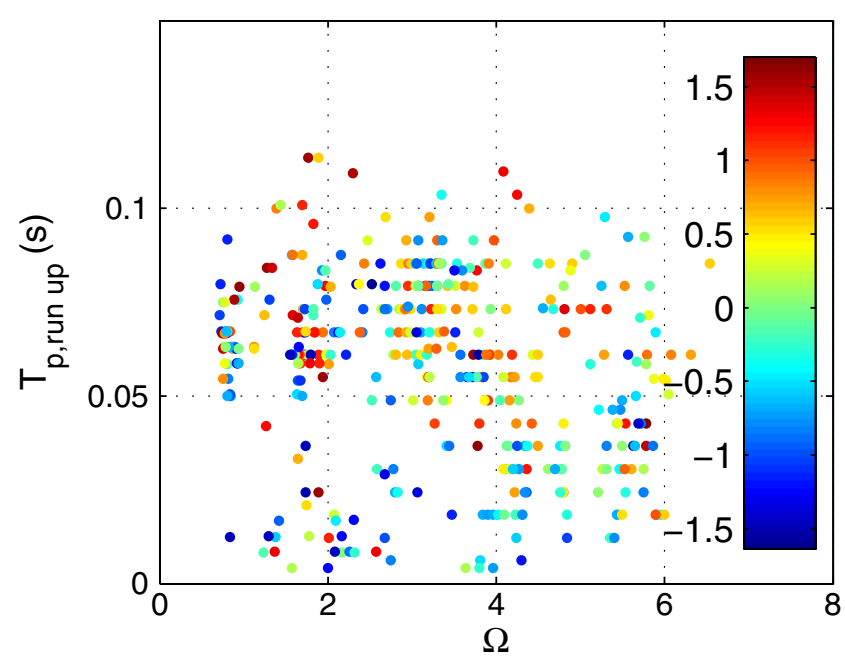

Fig. 9 Scatter plot of the peak run-up frequency vs the nondimensional sediment fall velocity $\Omega$ (e). Color scale expresses the tidal level 
Moreover, swash is driven by a variety of waves: breaking and non-breaking short waves (sea and swell), as well as longer, non-breaking ones, i.e., leaky-mode standing waves and standing and progressive edge waves (e.g., Holland et al. 1995). In most wave run-up parameterizations, offshore wave statistical and spectral parameters (e.g., $H_{\mathrm{s}}, T_{\mathrm{p}}$ ) are used to express the energy of the entire offshore wave spectrum, which is a simplification and possible source of errors. The wave buoy is recording wave data on the other side of the cape (Fig. 1), a fact which could question the validity of the measurements for non-synoptic events. On the other hand, the wave regime of the study area consists almost exclusively of WSW and SE waves, and the buoy measurements at the cape have been shown to be representative of the offshore wave conditions for Faro Beach. Moreover, even if SE waves nearshore Faro Beach are affected by increased refraction, they are less important in terms of overwash and hazards than WSW ones which are typically of longer period and more energetic.

The beach slope or the Iribarren number is typically parameter expressing the capacity of the beach morphology to gradually dissipate the (mostly-incident frequency band) wave energy before reaching the shore. However, this can be a serious simplification and the correlation between the peak run-up period and $\xi$ was very weak for values $\xi<1.5$, which characterized a significant part of the present dataset (Fig. 3d).While wave shoaling/breaking takes place mostly at the surf zone, most wave run-up parameterizations were based on the beach-face slope. The main reason is that the dry/intertidal beach is more accessible than the submerged profile for topographic surveying. However, using the beachface slope is a possible source of errors, since it does not always express the shape of the surf zone bathymetry.

Several previous studies report that swash motions are dominated by energy found in the low-frequency band $\left(0.005 \mathrm{~Hz}<f_{\text {swash }}<0.1 \mathrm{~Hz}\right)$, and the ratio of the infragravityto-incident frequency energy contributions to the total swash spectra has been typically found to exceed $E_{\text {infral }}$ $E_{\text {inci }}>0.8$ (Erikson et al. 2006; Holman and Guza 1984; e.g., Baldock and Holmes 1999; Mase 1988). However, the values from the steep, Faro Beach were lower (Fig. 6a), and the low-frequency contributions were more significant mainly during storm conditions, when the surf zone was saturated.

For the present dataset, the $R_{2}$ prediction errors of the best-fit parameterization (Eq. 7) were found to be loosely related to the tidal variations (Fig. $10 \mathrm{~g}$ ), and more specifically, $R_{2}$ was over-estimated for low tides and underestimated for high tides. Wave dissipation is expected to increase during low tides, and the results indicate that its poor representation resulted in residual errors. For the same reason, parameterizations including $\eta_{\text {tide }}$ improved the predictive capacity (see Table 2), since the tidal level probably added a "wave dissipation factor" to the fitting efforts. Similarly, isolating measurements for tidal levels above and below MSL decreased the RMS errors (Fig. 5), which were higher for the low tides, an indication that wave dissipation is not accurately expressed by the approach followed. On the other hand, more detailed wavepropagation estimations (e.g., using numerical models) would again suffer by inaccurately described surf zone bathymetry, which is the case for most engineering/research efforts requiring wave run-up height estimations.

Apart from $\eta_{\text {tide }}$, most other input parameters did not show to be correlated to the $R_{2}$ prediction error (e.g., $T_{\mathrm{p}}, \beta$, $U_{\text {wind, }, x}, T_{\text {p,run up }}$, see Fig. $10 \mathrm{~g}$ ), while many over-predicted values were related to values of $H_{\mathrm{s}}<1 \mathrm{~m}, \Omega<2$, and $\xi>2$. The above values are indicative of reflective beach state and occurrence of plunging breakers. It is important to note that many of the parameters found in the literature express analytical solutions, supported by theoretical concepts, while others are the result of data-driven approaches. The latter is mostly the case for the presently followed approach as well, since the parameterizations derived on the grounds of conceptual models were outperformed by the equations generated by iterative fitting (Eq. 7).

The tidal level and the wind speed were introduced for the first time (according to our knowledge) and showed to improve the parameterizations' predictive capacity (Table 2). As mentioned above, $\eta_{\text {tide }}$ is likely to have acted as a factor expressing the increased wave energy dissipation during low tides. The above process should have been also expressed by the beach-face slope (or $\xi$ ), which has the tendency to decrease moving from the profile section around the high tide mean water level to the section around low tide mean water level. However, the improvement of the results by including the tidal elevation implies that either the slope alone is not sufficient to express the variations of wave attenuation with mean water level or that the relationship between the two parameters is not linear and was better expressed with the addition of an extra term.

An interesting remark is that $U_{w, x}$ was incorporated in Eq. 10-12, multiplied by a negative fitting parameter, implying increasing $R_{2}$ with seaward wind velocities, while one would expect shoreward wind to be in favor of longer swash excursions. The negative coefficient value may represent a best-fit solution obtained from the iterative procedure for the given set of parameters, without having any physical meaning. On the other hand, wind is often an "underestimated" parameter which can have significant impact on both hydrodynamics and beach morphology (e. g., Masselink 1998). The direction and the magnitude of the local wind can affect breaker type, and onshore winds have been shown to cause waves to break in deeper depths and spill, whereas offshore winds cause waves to break in shallower depths and plunge (Douglass 1990). Spilling 

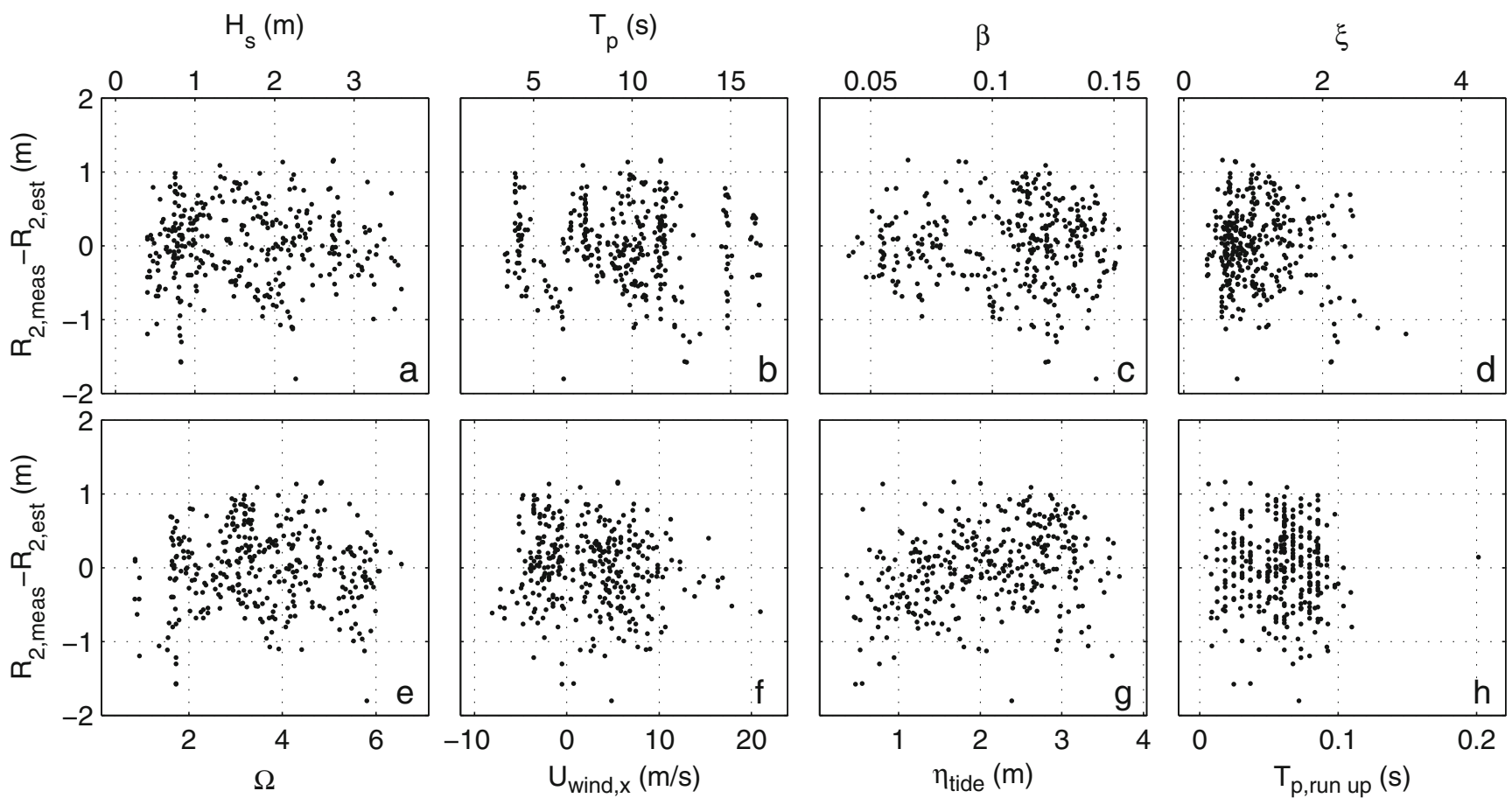

Fig. 10 Scatter plots of the wave run-up height $R_{2}$ error vs the significant wave height (a), peak wave period (b), beach-face slope (c), Iribarren number (d), non-dimensional sediment fall velocity (e),

shore-normal wind velocity component (f), tidal elevation (g), and the peak run-up frequency (h)

breakers generate less turbulence and less intense local fluid motions than plunging or collapsing breakers, which act as free-falling jets driving sediment suspension and scour (Lin and Liu 1998; Ting and Kirby 1995). On the other hand, spilling breakers tend to travel along longer sections, and the surf zone integrated wave dissipation could eventually be higher than the one of plunging waves, implying reduced energy level at the swash initiation.

Onshore wind can also indirectly affect wave shoaling/ breaking through wind setup, which when intense tends to form two-dimensional pressure gradients and rip currents. The latter can interact with waves and attenuate them, while they can also alter beach slope and width through the formation of cusp systems (MacMahan et al. 2005, 2006). All the above justify the estimated negative fitting coefficient for $U_{w, x}$ and imply that it is a parameter that should be considered for wave runup height estimations. Parameterizations combining $U_{w, x}$ and $\eta_{\text {tide }}$ produced also reasonable RMS errors $(0.51 \mathrm{~m}$, see Table 2), a fact which can be justified by the good correlation between the wind speed and the significant wave height.

\subsection{Dune overwash predictions}

The dune overwash predictions were realistic, and the identified vulnerable areas came in good agreement with field observations and previous studies in the area (Almeida et al. 2011b; Ferreira et al. 2006). Even though a constant beach-face slope value was considered for the entire study

area, during the dune overwash predictions, the approach could be easily modified for alongshore variable $\beta$. However, we do not feel that such a modification would improve significantly the accuracy of the predictions for the present study site, since Faro Beach is very dynamic and beach profile pivoting can be very fast during storm conditions, making $\beta$ a parameter which cannot be easily assessed. Thus, we feel that avoiding errors due to the inaccurate beach-face slope definition is inevitable, especially given the fact that beach cusp systems are very variable. However, the use of alongshore variable $\beta$ would make sense for sites which are either less dynamic, or where an intensive topographic monitoring scheme is active.

Furthermore, we should note that the predictions are based at the topography of the study area during the 20092010 winter and that the dune/beach morphology can change either due to storm induced erosion, or anthropogenic factors. While incorporating recently updated topographic data can improve the predictions' accuracy, one of the shortcomings of using empirical wave run-up height parameterizations lies on the fact that they were derived assuming cross-shore constant beach-face slope and sediment characteristics. This is not the case for dune-backed beaches where the beach-face gradient is significantly lower than the one of the dune-face. For the case of Faro Beach, cross-shore slope variations are not very high, since dunes have been, to a large extent, depleted and/or occupied by beach infrastructure. 
On the other hand, the active beach width has been reduced at the area around the parking $(-200 \mathrm{~m}<y<100 \mathrm{~m}$, e.g., Fig. 11) where intense human intervention took place, mostly related to the installation of pavements and/or artificial dunes based on boulders. At these sections, swash excursions take place over parts of the sandy beach face and are usually restricted by the above structures. Locations with exposed boulders have increased porosity, and thus, some capacity to attenuate swash energy and mitigate overwash events. On the other hand, this is not the case for the impermeable wall seaward the parking, where overwash events take place several times per year, even under nonstorm conditions (Almeida et al. 2011b).

The main advantage of the methodology followed is that it is simple, and it can be applied at the numerous study sites where data from coastal video monitoring stations exist. Moreover, the GUI timestack processing application has been designed in a way to easily allow modifications and different image-processing algorithms, which potentially could be more efficient at sites with different

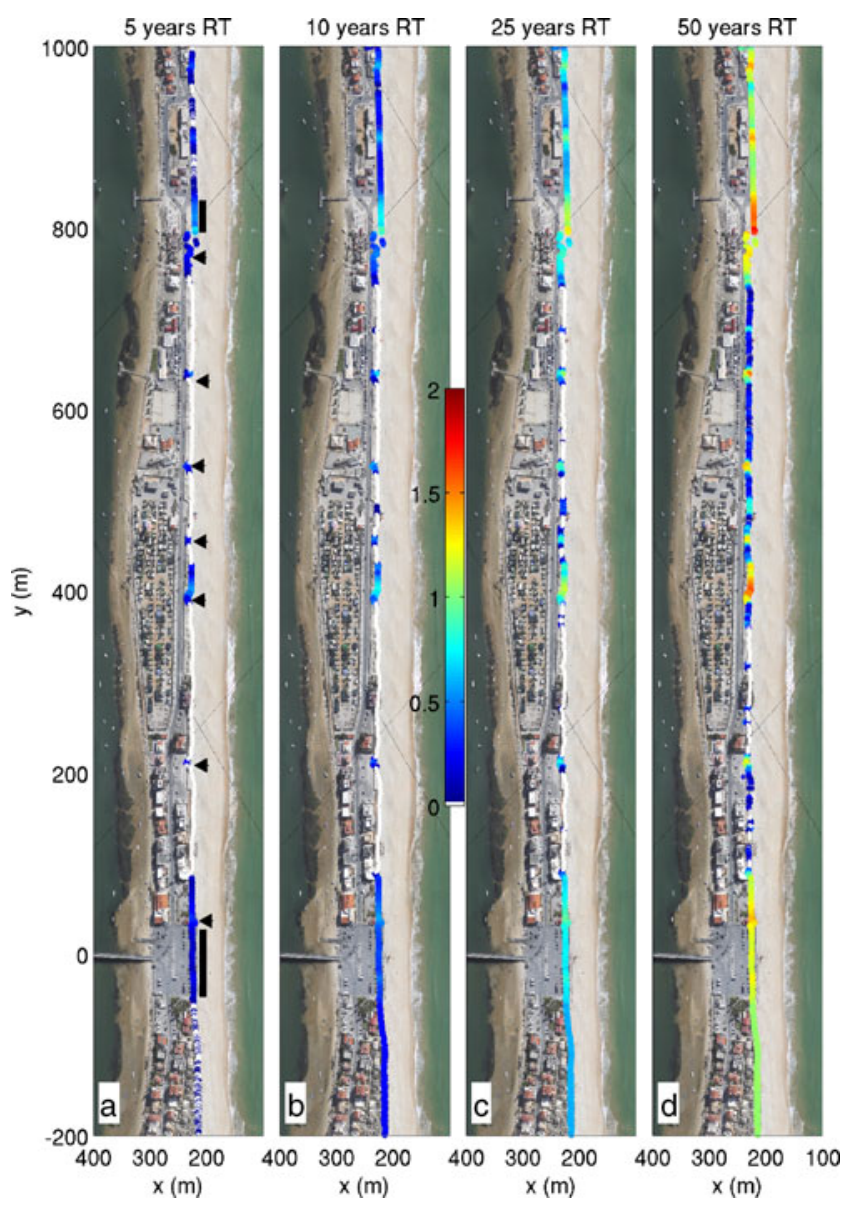

Fig. 11 Overwash maps of Faro Beach for storms with return period of 5 (a), 10 (b), 25 (c), and 50 years (d). Color scale indicates the excess total run-up height, relative to the maximum dune/seawall elevation, and white lines express the maximum swash excursion limit, in cases of no overwash environmental conditions than Faro Beach. Wave set-up estimations using the Boussinesq model could be easily substituted by empirical formulations (e.g., Stockdon et al. 2006) for the sake of simplicity.

Sallenger (2000) developed a storm-impact scaling model that used the relationship between water levels and the dune base and crest elevations, to define four storm-impact regimes: swash, collision, overwash, and inundation. The wave run-up parameterizations proposed for the present study could be very helpful to implement the above approach in a more accurate way. For the case of the tested extreme events (Fig. 11), only two regimes occurred: collision and overwash.

\section{Conclusions}

Timestack images generated from a coastal video monitoring station installed at Faro Beach, S Portugal were processed in GUI software, developed in MATLAB, to extract and process time series of the cross-shore position of the swash extrema. A dataset of $456 R_{2}$ measurements was used to form empirical wave run-up parameterizations using as input previously proposed expressions, and the obtained RMS errors from the best-fit cases were around $0.39 \mathrm{~m}$.

The $R_{2}$ prediction capacity improved when the shorenormal wind speed component and/or the tidal elevation $\eta_{\text {tide }}$ were included in the parameterizations, further reducing the RMS errors to $0.364 \mathrm{~m}$. Introducing the tidal level allowed a more accurate representation of the increased wave energy dissipation during low tides, while the negative trend between $R_{2}$ and the shore-normal wind speed component is probably related to the wind effect on wave breaking.

The ratio of the infragravity-to-incident frequency energy contributions to the total swash spectra were in general lower that the ones reported in the literature $E_{\text {infra }} / E_{\text {inci }}>0.8$, since lowfrequency contributions at the steep, reflective Faro Beach become more significant mainly during storm conditions.

An additional parameterization for the total run-up elevation was derived considering only 222 measurements for which $\eta_{\text {total }, 2}$ exceeded $2 \mathrm{~m}$ above MSL and the best-fit case resulted in RMS error of $0.41 \mathrm{~m}$. The equation was applied to predict overwash along Faro Beach for four extreme storms scenarios and the percentage of predicted overwashed beach ranged from $36 \%$ to $75 \%$, corresponding to maximum excess run-up elevation values up to $1.8 \mathrm{~m}$.

Acknowledgments The authors gratefully acknowledge European Community Seventh Framework Programme funding under the research project MICORE (grant agreement No. 202798). We are also indebted to the Restaurant "Paquete" for allowing us to deploy the cameras on their rooftop and for supplying electric power and space for our equipment. We are also thankful to Dr. Oscar Ferreira for the help and support, to Dr. Rui Taborda for providing the video cameras, and to Dr. Andre Pacheco, Umberto Andriolo, and Fotis Psaros for their contributions in the fieldwork. 


\section{Appendix: The graphical user interface timestack processing application}

Application window

The GUI MATLAB application is freely available from the following link: https://sourceforge.net/projects/guitimestack.

The program is initiated by the GUI_timestack command though the MATLAB command prompt, and the main window consists of five panels, the options of which are described below:

Timestack panel

The upper panel displaying the timestack, the extracted swash excursion tracks, and the individual peaks expressing the extrema points of each identified sash front

Additional plots panel

Includes (a) a plot showing the beach profile, the $R_{2}$, $R_{\max }$, and $\eta_{\text {tide }}$ levels, as well as the limits of the profile section considered for beach-face slope estimation and (b) a plot showing the wave run-up spectra

General options panel

Involves basic settings before the actual timestack processing steps:

"Select data path"- setting the path of the input data files

"Select file" - selecting a specific data file to process

"Start from"- -selecting the number of the initial data file to process (valid for the "Select data path" option)

"Next", "Previous"-allow browsing through the data files. Important: All extracted information are discarded

Swash tracking panel

Gives the possibility to the user to enhance check the quality of the extracted data:

"Set limit" - the user can reduce the "vertical dimensions" of the active timestack area for image processing by clicking twice with the mouse. It is useful since in zooming on the image section containing the swash motions, the performance of the swash extraction algorithm increases significantly.

"Clear"- deletes all the swash tracking results

"Restart"- restarts the timestack processing procedure, deleting the existing data for the specific data file

"Manual mode"-allows manual corrections on the extracted swash lines; after "Clear," it allows completely manual identification
Export options panel

Involves actions following the data extraction procedure related to data export:

"Clean R 2"- deletes the estimated $R_{2}$ value from the data file with the final results

"Flag"-is an option to mark bad quality images and export them in a separate "Flagged" directory

"Save \& continue"- exports the data output file to the "Exports" directory and initiates the processing of the following input data file

"Quit"- terminates the program

Import data files

In order to process timestack images using the GUI MATLAB application, the data have to be organized in separate MATLAB structure files named "stack." Once the data path is set, the program will search and open and contained .mat files so only the timestack files should be included in the data directory. The "stack" structure should include the following variables:

stack the time stack image $n x \times n t$, where $n x$ expresses the number of grid points along the beach transect considered for timestack generation and $n t$ the number of individual snapshots processed to generate the timestack image

$x, z \quad$ cross-shore real-world coordinates and elevation of the beach transect considered for timestack generation

Hs corresponding significant wave height

$\mathrm{Tp} \quad$ corresponding peak wave period

Dir corresponding wave direction

lev corresponding tidal elevation

date corresponding date

time corresponding time

gen_sdate corresponding MATLAB serial date (one value)

sdate time series of MATLAB serial date corresponding to the acquisition time of the individual snapshots processed to generate the timestack image

Export data files

The data output is included in an "exprt" structure file with the following variables:

$\mathrm{R}$ time series of the wave run-up elevation

tsecs time series of the corresponding time in seconds

R2 estimated $R_{2}$ value

Rmax $\quad$ estimated $R_{\max }$ value 
spectra.f frequency variable of the estimated wave run-up spectra

spectra. spectral density variable of the estimated wave $\mathrm{Y} \quad$ run-up spectra

$\mathrm{Rx}$ time series of the cross-shore swash excursion position

$\mathrm{R} 2 \mathrm{x} \quad 2 \%$ exceedence value of the cross-shore swash excursion position

Rmax_x maximum cross-shore swash excursion position meta timestack metadata including the basic data input variables

\section{References}

Aagaard T, Holm D (1989) Digitization of wave runup using video records. J Coast Res 5:547-551

Almeida LP, Ferreira Ó, Pacheco A (2010) Thresholds for morphological changes on an exposed sandy beach as a function of wave height. Earth Surf Proc Landforms 36:523-532

Almeida LP, Ferreira Ó, Vousdoukas M, Dodet G (2011a) Historical variation and trends in storminess along the Portuguese south coast. Nat Hazards Earth Syst Sci. doi:10.5194/nhess-11-1-2011

Almeida LP, Vousdoukas MI, Ferreira ÓM, Rodrigues BA, Matias A (2011b) Thresholds for storm impacts on an exposed sandy coastal area in southern Portugal. Geomorphology. doi:10.1016/j. geomorph.2011.04.047

Baldock TE, Holmes P (1999) Simulation and prediction of swash oscillations on a steep beach. Coast Eng 36(3):219-242

Battjes JA (1974) Surf similarity. In: 14th Conference on Coastal Engineering. ASCE, pp 466-480

Bouguet J-Y (2007) Camera Calibration Toolbox for Matlab. http:// www.vision.caltech.edu/bouguetj/calib_doc/

Briganti R, Bellotti G, Franco L, De Rouck J, Geeraerts J (2005) Field measurements of wave overtopping at the rubble mound breakwater of Rome-Ostia yacht harbour. Coast Eng 52 (12):1155-1174

Dean RG (2001) Beach nourishment: theory and practice. Advanced series on ocean engineering. World Scientific, London

Douglass SL (1990) Influence of wind on breaking waves. J Waterw Port Coast Ocean Eng 116(6):651-663

Douglass SL (1992) Estimating extreme values of run-up on beaches. J Waterw Port Coast Ocean Eng 118(2):220-224

Erikson LH, Hanes DM, Barnard PM, Gibbs AE (2006) Swash zone characteristics at Ocean Beach, San Francisco, CA. In: 30th International Conference on Coastal Engineering, Los Angeles

Ferreira Ó, Vousdoukas MV, Ciavola P (2009) MICORE review of climate change impacts on storm occurrence (open access, Deliverable WP1.4). https://micore.eu/area.php?idarea $=28$

Ferreira Ó, Garcia T, Matias A, Taborda R, Dias JA (2006) An integrated method for the determination of set-back lines for coastal erosion hazards on sandy shores. Cont Shelf Res 26 (9):1030-1044

Folk RL (1980) Petrology of the sedimentary rocks. Hemphill, Austin

Fredsoe JE, Deigaard R (1992) Mechanics of coastal sediment transport. Advanced series on ocean engineering. World Scientific, London

Hartley R, Zisserman A (2006) Multiple view geometry in computer vision. Cambridge University Press, Cambridge

Holland KT, Holman RA (1991) Measuring run-up on a natural beach II. EOS Trans Am Geophys Union 72:254
Holland KT, Holman RA (1993) The statistical distribution of swash maxima on natural beaches. J Geophys Res 87:10271-10278

Holland KT, Raubenheimer B, Guza RT, Holman RA (1995) Run-up kinematics on a natural beach. J Geophys Res 100(C3):4985-4993

Holman RA (1986) Extreme value statistics for wave run-up on a natural beach. Coast Eng 9:527-544

Holman RA, Guza RT (1984) Measuring run-up on a natural beach. Coast Eng 8:129-140

Holman RA, Stanley J (2007) The history and technical capabilities of Argus. Coast Eng 54(6-7):477-491

Hunt IA (1959) Design of seawalls and breakwaters. J Waterw Harb Div ASCE 85(WW3):123-152

Iribarren CR, Nogales C (1949) Protection des Ports. In: XVIIth International Navigation Congress, Lisbon, Portugal

Karambas TV, Koutitas C (2002) Surf and swash zone morphology evolution induced by nonlinear waves. J Waterw Port Coast Ocean Eng 128(3)

Korycansky DG, Lynett PJ (2007) Run-up from impact tsunami. Geophys J Int 170:1076-1088

Kroon A, Davidson MA, Aarninkhof SGJ, Archetti R, Armaroli C, Gonzalez M, Medri S, Osorio A, Aagaard T, Holman RA, Spanhoff R (2007) Application of remote sensing video systems to coastline management problems. Coast Eng 54(6-7):493-505

Larson M, Kubota S, Erikson L (2004) Swash-zone sediment transport and foreshore evolution: field experiments and mathematical modeling. Mar Geol 212(1-4):61-79

Lin P, Liu PL-F (1998) A numerical study of breaking waves in the surf zone. J Fluid Mech 359:239-264

MacMahan JH, Thornton EB, Stanton TP, Reniers AJHM (2005) RIPEX: observations of a rip current system. Mar Geol 218 (1-4):113-134. doi:10.1016/j.margeo.2005.03.019

MacMahan JH, Thornton EB, Reniers AJHM (2006) Rip current review. Coast Eng 53(2-3):191-208

Mase H (1988) Spectral characteristics of random wave run-up. Coast Eng 12:175-189

Masselink G (1998) The effect of sea breeze on beach morphology, surf zone hydrodynamics and sediment resuspension. Mar Geol 146(1-4):115-135

Mei CC (1994) The applied dynamics of ocean surface waves. In: Advanced series on ocean engineering, vol. 1. World Scientific, London

Munoz-Perez JJ, de San L, Roman-Blanco B, Gutierrez-Mas JM, Moreno L, Cuena GJ (2001) Cost of beach maintenance in the Gulf of Cadiz (SW Spain). Coast Eng 42(2):143-153

Otsu N (1979) A threshold selection method from gray-level histograms. IEEE Trans Syst Man Cybern 9:62-66

Pearre NS, Puleo JA (2009) Quantifying seasonal shoreline variability at Rehoboth Beach, Delaware, using automated imaging techniques. J Coast Res 25(4):900-914

Pires HO (1998) Preliminary report on the wave climate at Faro. Project India. Instituto de Meteorologia-Instituto Superior Técnico, Portugal

Raubenheimer B, Guza RT (1996) Observations and predictions of runup. J Geophys Res 101:25575-25587

Ruessink BK, Kleinhans MG, van den Beukel PGL (1998) Observations of swash under highly dissipative conditions. J Geophys Res 103:3111-3118

Ruggiero P, Komar PD, McDougal WG, Marra JJ, Beach RA (2001) Wave runup, extreme water levels and the erosion of properties backing beaches. J Coast Res 17(2):407-419

Ruggiero P, Holman RA, Beach RA (2004) Wave run-up on a highenergy dissipative beach. J Geophys Res 109(C06025). doi:10.1029/2003JC002160

Sallenger AH (2000) Storm impact scale for barrier islands. J Coast Res 16:890-895

Schaffer HA, Madsen PA, Deigaard R (1993) A Boussinesq model for waves breaking in shallow water. Coast Eng 20:185-202 
Smith KR, Bryan KR (2007) Monitoring beach volume using a combination of intermittent profiling and video imagery. J Coast Res 23(4):892-898

Stockdon HF, Holman RA, Howd PA, Sallenger JAH (2006) Empirical parameterization of setup, swash, and runup. Coast Eng 53 (7):573-588

Synolakis CE (1987) The run-up of solitary waves. J Fluid Mech 185:523-555

Ting FCK, Kirby JT (1995) Dynamics of surf-zone turbulence in a strong plunging breaker. Coast Eng 24(3-4):177-204

US Army Corps of Engineers (2002) Coastal engineering manual. Engineer manual 1110-2-1100 (in 6 volumes). US Army Corps of Engineers, Washington, DC

Veeramony J, Svendsen IA (2000) The flow in surf-zone waves. Coast Eng 39(2-4):93-122

Velegrakis AF, Vousdoukas MI, Vagenas AM, Karambas T, Dimou K, Zarkadas T (2007) Field observations of waves generated by passing ships: a note. Coast Eng 54:369-375
Vousdoukas MI, Velegrakis AF, Dimou K, Zervakis V, Conley DC (2009a) Wave run-up observations in microtidal, sedimentstarved pocket beaches of the Eastern Mediterranean. J Mar Syst 78(Supplement 1):S37-S47

Vousdoukas MI, Velegrakis AF, Karambas TV (2009b) Morphology and sedimentology of a microtidal, beachrock-infected beach: Vatera Beach, Lesvos, NE Mediterranean. Cont Shelf Res 29 (16): 1937-1947

Vousdoukas MI, Ferreira PM, Almeida LP, Dodet G, Andriolo U, Psaros F, Taborda R, Silva AN, Ruano AE, Ferreira Ó (2011) Performance of intertidal topography video monitoring of a meso-tidal reflective beach in South Portugal. Ocean Dyn. doi:10.1007/s10236-011-0440-5

Wright LD, Short AD (1984) Morphodynamic variability of surf zones and beaches: a synthesis. Mar Geol 56(1-4):93118

Xue C (2001) Coastal erosion and management of Majuro Atoll, Marshall Islands. J Coast Res 17(4):909-918 